PREPARED FOR THE U.S. DEPARTMENT OF ENERGY, UNDER CONTRACT DE-AC02-76CH03073

PPPL-3730

PPPL-3730

UC-70

Trapped Electron Precession Shear Induced Fluctuation Decorrelation

by

T.S. Hahm, P.H. Diamond, and E.-J. Kim

July 2002

NM|

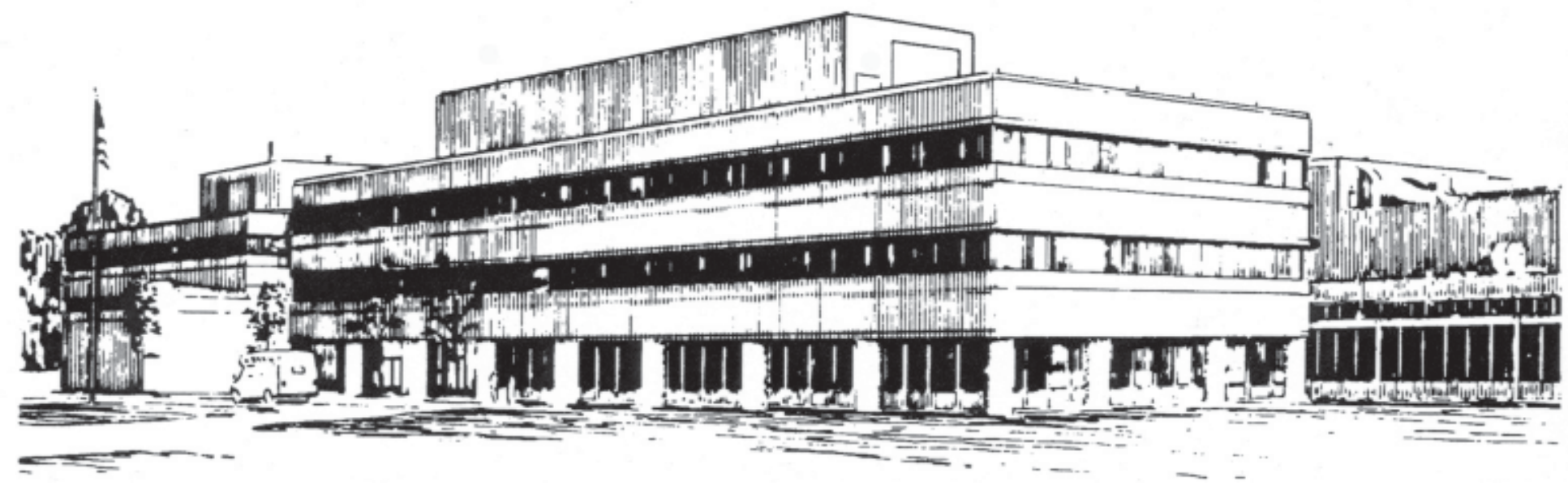

PRINCETON PLASMA PHYSICS LABORATORY PRINCETON UNIVERSITY, PRINCETON, NEW JERSEY 


\section{PPPL Reports Disclaimer}

This report was prepared as an account of work sponsored by an agency of the United States Government. Neither the United States Government nor any agency thereof, nor any of their employees, makes any warranty, express or implied, or assumes any legal liability or responsibility for the accuracy, completeness, or usefulness of any information, apparatus, product, or process disclosed, or represents that its use would not infringe privately owned rights. Reference herein to any specific commercial product, process, or service by trade name, trademark, manufacturer, or otherwise, does not necessarily constitute or imply its endorsement, recommendation, or favoring by the United States Government or any agency thereof. The views and opinions of authors expressed herein do not necessarily state or reflect those of the United States Government or any agency thereof.

\section{Availability}

This report is posted on the U.S. Department of Energy's Princeton Plasma Physics Laboratory Publications and Reports web site in Fiscal Year 2002. The home page for PPPL Reports and Publications is: http://www.pppl.gov/pub_report/

DOE and DOE Contractors can obtain copies of this report from:

U.S. Department of Energy

Office of Scientific and Technical Information

DOE Technical Information Services (DTIS)

P.O. Box 62

Oak Ridge, TN 37831

Telephone: (865) 576-8401

Fax: (865) 576-5728

Email: reports@adonis.osti.gov

This report is available to the general public from:

National Technical Information Service

U.S. Department of Commerce

5285 Port Royal Road

Springfield, VA 22161

Telephone: 1-800-553-6847 or

(703) 605-6000

Fax: (703) 321-8547

Internet: http://www.ntis.gov/ordering.htm 


\title{
Trapped Electron Precession Shear Induced Fluctuation Decorrelation
}

\author{
T.S. Hahm ${ }^{a}$, P.H. Diamond ${ }^{b}$, and E.-J. Kim ${ }^{b}$ \\ June 11, 2002
}

${ }^{a}$ Princeton Plasma Physics Laboratory, PO Box 451, Princeton, NJ 08543, USA

${ }^{b}$ University of California at San Diego, La Jolla, CA 92093-0319, USA

We consider the effects of trapped electron precession shear on the microturbulence. In a similar way the strong $\mathbf{E} \times \mathbf{B}$ shear reduces the radial correlation length of ambient fluctuations, the radial variation of the trapped electron precession frequency can reduce the radial correlation length of fluctuations associated with trapped electrons. In reversed shear plasmas, with the explicit dependence of the trapped electron precession shearing rate on $B_{\theta}$, the sharp radial gradient of $T_{e}$ due to local electron heating inside $q_{\min }$ can make the precession shearing machanism more effective, and reduce the electron thermal transport constructing a positive feedback loop for the $T_{e}$ barrier formation.

\section{Introduction}

There is accumulating evidence[1] that the $\mathbf{E} \times \mathbf{B}$ shear induced decorrelation of turbulence[2,3] is responsible for the formation of internal transport barriers (ITB) in ion thermal transport channel. However understanding different behavior of electron thermal transport still remains one of the most challenging problems in tokamak confinement physics. While there has been revived interest in small scale electron temperature gradient (ETG) turbulence recently, qualitative difference in nonlinear simulation results[4] and the implications of the high-k fluctuation data[5] from experiments cast lingering doubts on the dominance of ETG turbulence driven transport in tokamaks.

The particular channels exhibiting ITB formation often respond to the $\mathbf{E} \times \mathbf{B}$ shear and $q$ profiles differently[6]. In some cases, with reversed magnetic shear, the barriers in $T_{i}, n_{e}$ and $T_{e}$ form simultaneously at the same location where the $\mathbf{E} \times \mathbf{B}$ shearing rate is high [7]. In many cases, the strong barriers in $T_{i}$ and $n_{e}$ can form with only a weak or no barrier in $T_{e}$ [8]. In ion-heated plasmas, $T_{e}$ is typically most resistant to forming ITBs. 
Strong $T_{e}$ ITBs are in general associated with strong electron local heating and reversed magnetic shear[9] sometimes with high triangularity[10]. Therefore it is natural to seek a mechanism other than the $\mathbf{E} \times \mathbf{B}$ shear, which is effective in reducing $\chi_{e}$ significantly when the following experimental conditions are realized.

i) $T_{e}>T_{i}$ and low collisionality such that the collisionless trapped electron mode could be important; typical of low density electron heated plasmas,

ii) reversed magnetic shear in the core typical of LHCD, and ECCD discharges.

Often relatively long wavelength density fluctuations which are measured by reflectometry tend to decrease (rather than completely quenched) either in radial correlation length[11] or in amplitude[12] when $T_{e}$ ITB is formed. These observations motivate us to seek a robust nonlinear mechanism which is relatively insensitive to the details of linear stability of specific modes, and which is applicable to plasmas ranging from near circular low- $\beta$ plasmas such as Tore Supra to strongly shaped high- $\beta$ plasmas. We consider the effects of trapped electron precession shear on the electrostatic fluctuations in the range of $k_{\perp} \rho_{i} \sim 1$.

\section{Radial Decorrelation due to Trapped Electron Precession Shear}

Following the previous work[13] on the trapped electron dynamics, we start from an electrostatic bounce averaged drift kinetic equation in which the non-adiabatic part of the perturbed trapped electron distribution function $\delta H \equiv \delta f_{e}-\frac{e \phi}{T_{e}} F_{0}$ is convected by the precession drift $\mathbf{V}_{\mathbf{d e}}$, and the fluctuating $\mathbf{E} \times \mathbf{B}$ velocity $\tilde{\mathbf{V}}_{E}$,

$$
\left(\partial / \partial t+\mathbf{V}_{\mathbf{d e}} \cdot \nabla+\tilde{\mathbf{V}}_{\mathbf{E}} \cdot \nabla\right) \delta \mathbf{H}=\mathbf{i}\left\{\omega_{* \mathbf{e}}\left(\mathbf{1}+\eta_{\mathbf{e}}\left(\epsilon / \mathbf{T}_{\mathbf{e}}-\mathbf{3} / \mathbf{2}\right)\right)-\omega\right\} \frac{\mathbf{e} \phi}{\mathbf{T}_{\mathbf{e}}} \mathbf{F}_{\mathbf{0}},
$$

where $\tilde{\mathbf{V}}_{\mathbf{E}}=\mathbf{B} \times \nabla \delta \boldsymbol{\Phi} / \mathbf{B}^{2}$, other notations are standard. We note that $\mathbf{V}_{\mathbf{d e}} \cdot \nabla=$ $\mathrm{ik} \mathrm{k}_{\perp} \cdot \mathbf{V}_{\mathbf{d e}} \equiv \mathrm{i} \omega_{\mathrm{De}} \equiv \omega_{\mathbf{D} \phi} \partial_{\phi}$. Here, the trapped electron precession frequency $\omega_{D \phi}$ is related to more commonly used one $\omega_{D e}$ by $\omega_{D e}=n \omega_{D \phi}$ where $n$ is the toroidal mode number.

The two-point correlation evolution equation is then derived following the standard procedure of symmetrization with respect to $\left(\psi_{1}, \phi_{1}, \epsilon_{1}, \kappa_{1}\right)$ and $\left(\psi_{2}, \phi_{2}, \epsilon_{2}, \kappa_{2}\right)$ followed by an ensemble average.

$$
\left\{\frac{\partial}{\partial t}+\psi_{-} \Omega_{\psi} \frac{\partial}{\partial \phi_{-}}+\epsilon_{-} \Omega_{\epsilon} \frac{\partial}{\partial \phi_{-}}+\kappa_{-} \Omega_{\kappa} \frac{\partial}{\partial \phi_{-}}-D_{-}^{\mathrm{eff}} \frac{\partial^{2}}{\partial \phi_{-}^{2}}\right\}<\delta H(1) \delta H(2)>=S_{2}
$$

Here, the radial shear of the precession frequency in toroidal direction is given by

$$
\Omega_{\psi} \equiv-\frac{\partial}{\partial \psi} \omega_{D \phi}\left(\psi_{+}, \epsilon_{+}, \kappa_{+}\right)
$$


Additionally, the variations of precession frequency in energy and pitch angle variable are characterized by $\Omega_{\epsilon}$ and $\Omega_{\kappa}$ respectively. In Eq. (2), $S_{2}=<\delta H(1) S(2)>+<$ $\delta H(2) S(1)>$ is the source term for the two-point correlation function and the $\mathbf{E} \times \mathbf{B}$ nonlinearity is approximated as a turbulent diffusion along the perpendicular direction which vanishes at zero separation[14]. The decorrelation dynamics due to the coupling of the precession shear in phase space and turbulent diffusion can be studied by taking various moments of the left hand side (lhs) of Eq. (2). By calculating the eddy lifetime which is a function of the initial separation between two nearby points, one can derive that The radial correlation length $\Delta r_{t} \equiv \Delta \psi / R B_{\theta}$, is reduced by the flow shear relative to its value $\Delta r_{0} \equiv \Delta \psi_{0} / R B_{\theta}$, determined by ambient turbulence alone:

$$
\left(\frac{\Delta \psi_{0}}{\Delta \psi}\right)^{2}=1+\frac{\omega_{P S}^{2}}{\Delta \omega_{T}^{2}}
$$

Therefore, we expect that fluctuation suppression occurs when the decorrelation rate of the ambient turbulence $\Delta \omega_{T}$ is exceeded by the precession shearing rate, $\omega_{P S}$ :

$$
\omega_{P S} \equiv \frac{\Delta \psi_{0}}{\Delta \phi} \frac{\partial}{\partial \psi} \omega_{D \phi}(\psi, \epsilon, \kappa)=\frac{\Delta \psi_{0}}{\Delta \phi} \frac{\partial}{\partial \psi}\left(\frac{c T_{e} G(\kappa)}{e B_{\theta} R^{2}}\right)=\frac{\Delta r_{0}}{\Delta l_{\perp}} \frac{\left(R B_{\theta}\right)^{2}}{B} \frac{\partial}{\partial \psi}\left(\frac{c T_{e} G(\kappa)}{e B_{\theta} R^{2}}\right)
$$

where $G(\kappa)$ is the pitch angle dependence of the precession frequency which varies from 1 for deeply trapped particles to -1 for particles near trapped-passing boundary. We note that this mechanism works for both resonant and non-resonant (interchangetype) trapped electron driven turbulence, without relying on the linearly stabilizing influence of the trapped electron precession reversal[15]. In reversed shear plasmas, with the explicit dependence of $\omega_{P S}$ on $B_{\theta}$, the sharp radial gradient of $T_{e}$ due to local electron heating inside $q_{\text {min }}$ can make $\omega_{P S}$ higher, and reduce the electron thermal transport constructing a positive feedback loop for the $T_{e}$ barrier formation.

\section{Acknowledgments}

The authors would like to acknowledge the international workshop "Self Organization and Transport in Electromagnetic Turbulence" held in Aix-en-Provence, France in July 2001 where part of this research has been performed. This work was supported by the U.S. Department of Energy Contract No. DE-AC02-76-CHO-3073 and the U.S. Department of Energy Contract No. DE-FG03-88ER 53275.

\section{References}

[1] K.H. Burrell, Phys. Plasmas, 4, 1499 (1997);

E.J. Synakowski et al., Phys. Plasmas 4, 1736 (1997).

[2] H. Biglari, P.H. Diamond, and P.W. Terry, Phys. Fluids B 2, 1 (1990). 
[3] T.S. Hahm and K.H. Burrell, Phys. Plasmas 2, 1648 (1995).

[4] P.H. Diamond, Electron Thermal Transport, A preview talk at the 15th US Transport Task Force meeting, Annapolis, MD, USA (2002).

[5] K.L. Wong et al., Phys. Lett. A 236, 339 (1997).

[6] T.S. Hahm, Plasma Phys. Control. Fusion 44, A87 (2002).

[7] F.X. Soldner and JET team, Plasma Phys. Control. Fusion 39, B353 (1998);

E.J. Doyle et al., Plasma Phys. Control. Fusion 42, A236 (2000).

[8] F.M. Levinton et al., Phys. Rev. Lett. 80, 4887 (1998).

[9] X. Litaudon et al., Plasma Phys. Controlled Fusion 38, 1603 (1996);

T. Fujita et al., Phys. Rev. Lett. 782377 (1997);

V. Parail et al., Nucl. Fusion, 39, 1743 (1999);

C.M. Greenfield et al., The 27th European Conference on Controlled Fusion and Plasma Physics, 24B, 544 (Budapest 2000);

R. Wolf et al., Nucl. Fusion 41, 1259 (2001).

[10] Y. Kamada, Plasma Phys. Controlled Fusion 42, A65 (2000).

[11] R. Nazikian et al., Plasma Phys. Controlled Nuclear Fusion Reserch (Vienna: IAEA) 1998.

[12] G.D. Conway et al., To appear in Plasma Phys. Controlled Fusion 44 (2002).

[13] F.Y. Gang and P.H. Diamond, Phys. Fluids B 2, 2976 (1990);

B.H. Fong and T.S. Hahm, Phys. Plasmas 6, 188 (1999).

[14] P.W. Terry and P.H. Diamond, Phys. Fluids, (1985).

[15] B.B. Kadomtsev and O.P. Pogutse, in Reviews of Plasma Physics, edited by M.A. Leontovich (Consultants Bureau, New York, 1970), Vol. 5;

M.A. Beer, PhD Thesis, Princeton University, 1995. 


\section{External Distribution}

Plasma Research Laboratory, Australian National University, Australia

Professor I.R. J ones, Flinders University, Australia

Professor J oão Canalle, Instituto de Fisica DEQ/IF - UERJ , Brazil

Mr. Gerson O. Ludwig, Instituto Nacional de Pesquisas, Brazil

Dr. P.H. Sakanaka, Instituto Fisica, Brazil

The Librarian, Culham Laboratory, England

Library, R61, Rutherford Appleton Laboratory, England

Mrs. S.A. Hutchinson, JET Library, England

Professor M.N. Bussac, Ecole Polytechnique, France

Librarian, Max-Planck-Institut für Plasmaphysik, Germany

J olan Moldvai, Reports Library, MTA KFKI-ATKI, Hungary

Dr. P. Kaw, Institute for Plasma Research, India

Ms. P.J . Pathak, Librarian, Insitute for Plasma Research, India

Ms. Clelia De Palo, Associazione EURATOM-ENEA, I taly

Dr. G. Grosso, Instituto di Fisica del Plasma, Italy

Librarian, Naka Fusion Research Establishment, J AERI, J apan

Library, Plasma Physics Laboratory, Kyoto University, J apan

Research Information Center, National Institute for Fusion Science, J apan

Dr. O. Mitarai, Kyushu Tokai University, J apan

Library, Academia Sinica, Institute of Plasma Physics, People's Republic of China

Shih-Tung Tsai, Institute of Physics, Chinese Academy of Sciences, People's Republic of China

Dr. S. Mirnov, TRINITI, Troitsk, Russian Federation, Russia

Dr. V.S. Strelkov, Kurchatov Institute, Russian Federation, Russia

Professor Peter Lukac, Katedra Fyziky Plazmy MFF UK, Mlynska dolina F-2, Komenskeho Univerzita, SK-842 15 Bratislava, Slovakia

Dr. G.S. Lee, Korea Basic Science Institute, South Korea

Mr. Dennis Bruggink, Fusion Library, University of Wisconsin, USA

Institute for Plasma Research, University of Maryland, USA

Librarian, Fusion Energy Division, Oak Ridge National Laboratory, USA

Librarian, Institute of Fusion Studies, University of Texas, USA

Librarian, Magnetic Fusion Program, Lawrence Livermore National Laboratory, USA

Library, General Atomics, USA

Plasma Physics Group, Fusion Energy Research Program, University of California at San Diego, USA

Plasma Physics Library, Columbia University, USA

Alkesh Punjabi, Center for Fusion Research and Training, Hampton University, USA

Dr. W.M. Stacey, Fusion Research Center, Georgia Institute of Technology, USA

Dr. J ohn Willis, U.S. Department of Energy, Office of Fusion Energy Sciences, USA

Mr. Paul H. Wright, Indianapolis, Indiana, USA 
The Princeton Plasma Physics Laboratory is operated by Princeton University under contract with the U.S. Department of Energy.

\author{
Information Services \\ Princeton Plasma Physics Laboratory \\ P.O. Box 451 \\ Princeton, NJ 08543
}

Phone: 609-243-2750

Fax: 609-243-2751

e-mail: pppl_info@pppl.gov

Internet Address: http://www.pppl.gov 